\title{
Trichomonosis in Eurasian sparrowhawks in the Czech Republic
}

\author{
Tomáš Kunca ${ }^{1}$, Pavla Smejkalová ${ }^{2}$ and Ivan Čepička² \\ ${ }^{1}$ Faculty of Environmental Sciences, Czech University of Life Sciences Prague, Prague, Czech Republic; \\ ${ }^{2}$ Faculty of Science, Department of Zoology, Charles University in Prague, Prague, Czech Republic
}

\begin{abstract}
Pigeon, doves and songbirds are hosts of the parasite Trichomonas gallinae (Rivolta, 1878), which causes avian trichomonosis. Raptors are infected when they digest infected prey. A high percentage of the diet of Eurasian sparrowhawk Accipiter nisus (Linnaeus) is comprised of birds. During the breeding season 2012 and 2013, we clinically tested 298 nestling Eurasian sparrowhawks from urban and rural areas of the Czech Republic for the presence of trichomonads. Sparrowhawk nestlings in the urban area were more infected (32.9\%) than in the rural area $(12.2 \%)$ in $2012\left(\chi^{2}=6.184, \mathrm{P}=0.045\right)$. The number of infected nestlings dropped in the urban area $(5.4 \%)$ and remained similar in the rural area (16.6\%) in 2013. Sequences of ITS region and SSU rDNA confirmed that the isolates from infected sparrowhawk nestlings belonged to Trichomonas gallinae.
\end{abstract}

Keywords: Accipiter nisus, avian trichomonosis, ITS region, Trichomonas gallinae, SSU rDNA

The Eurasian sparrowhawk Accipiter nisus (Linnaeus) is a common raptor that preferably breeds in woods and forests where it can find an abundance of prey (Newton 1986). Large cities also provide sufficient amounts of prey and sparrowhawks have been found to be breeding in various towns and cities across Europe (Fraissinet and Fulgione, 2008). Prague city has been colonised by sparrowhawks since the early 1980's and the population varies between 45-55 breeding pairs (Peške in Fuchs et al. 2002). The specificity of the urban environment brings some hazards such as a higher risk of collision and an increased concentration of diseases (Chase and Walsh 2006).

Urban pigeons and doves are frequently reported to be infected by various diseases including trichomonosis caused by Trichomonas gallinae (Rivolta, 1878) (Phan et al. 2013). Trichomonosis was also found in songbirds such as the European greenfinch, Carduelis chloris (Linnaeus), common chaffinch, Fringilla coelebs Linnaeus, hawfinch, Coccothraustes coccotraustes (Linnaeus), and Eurasian blue tit, Cyanistes caeruleus (Linnaeus) in western and northern Europe (Robinson et al. 2010). Since small and medium-sized birds comprise $97 \%$ of the sparrowhawk's diet during the breeding season (Newton 1986), the sparrowhawks have a high probability of encountering the parasite through ingestion of infected prey.

Modern molecular techniques allow genetic characterisation of the strains found in infected birds. By using the ITS region (ITS1-5.8S rDNA-ITS2) and SSU rDNA (small subunit ribosomal RNA gene), the diversity of the
Trichomonadidae has been examined in various studies (Kleina et al. 2004). However, only a few studies characterised T. gallinae from birds of prey using molecular data (Krone et al. 2005, Sansano-Maestre et al. 2009, Chi et al. 2013).

The main aim of the present study was to determine the prevalence of trichomonads in Eurasian sparrowhawks in the urban population of Prague and the rural population in northern Bohemia. A higher infection rate in urban sparrowhawks was suggested because of the high concentration of birds, especially pigeons (Fuchs et al. 2002). Additionally, we determined the genotype of trichomonads from sparrowhawks.

\section{MATERIALS AND METHODS}

The study was conducted in two areas. The first was an urban area of Prague, Czech Republic $\left(\sim 240 \mathrm{~km}^{2}-\right.$ a circle in the central Prague with a radius of $8.7 \mathrm{~km}$ ), where sparrowhawks breed in parks, gardens, cemeteries and urban greenery. The second study area was situated in the 'rural' Liberec region of north Bohemia, where sparrowhawks are found in large blocks of forest. The distance between the two areas is approximately $100 \mathrm{~km}$, which is large enough to eliminate any contact between the two populations during the breeding season (Fig. 1). The maximum home range size was found to be $12.3 \mathrm{~km}^{2}$ for females in Norway (Selas and Rafos 1999). In both areas the data collection was conducted during the breeding season from May to July 2012 and 2013. Sparrowhawks' nestlings (at the age of 20-24 days) were clinically tested for the presence of trichomonads using InPouch 


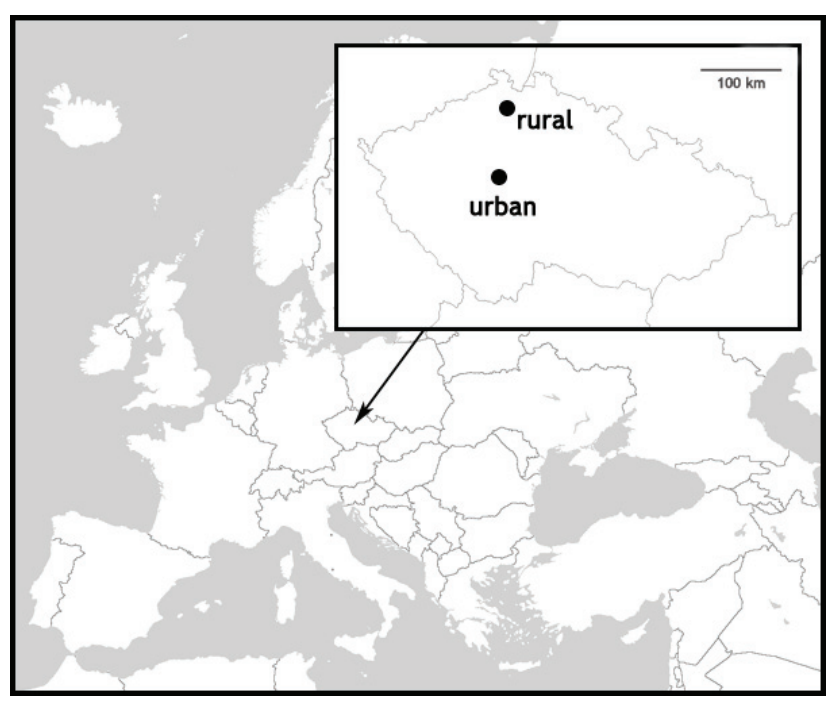

Fig. 1. Map of study areas in the Czech Republic.

TF Tritrichomonas foetus (Riedmüller, 1928) test kits (Biomed Diagnostics, San Jose, California, USA), suitable for diagnosis of Trichomonas gallinae (see Cover et al. 1994). Swab samples were collected from the oral cavity, transferred into the InPouch medium, cultured in $37^{\circ} \mathrm{C}$ for 6 days and examined microscopically $(100 \times$ magnification $)$ for the presence of motile protists. Selected cultures from 2013 positive for the presence of trichomonads were subsequently transferred into TYM medium (Diamond 1957). The cultures were maintained at $37^{\circ} \mathrm{C}$ and subcultured every 3-4 days. A genomic DNA Mini Kit (Blood/Cultured Cell) (Geneaid, New Taipei City, Taiwan) was used to isolate DNA from the cultures and lysate of smear from the oral cavity of one dead nestling (isolate from this dead nestling was marked ' $\mathrm{CB}$ '). Primers 16Sl (TACTTGGTTGATCCTGCC; Tachezy et al. 2002) and ITSF (TTCAGTTCAGCGGGTCTTCC; Čepička et al. 2005) were used to amplify SSU rDNA and ITS region together. The QIAquick PCR Purification Kit (Qiagen, Hilden, Germany) was used to purify the PCR products. Subsequently they were bidirectionally sequenced on the ABI Prism 3100-Avant Genetic Analyzer (Applied Biosystems, Waltham, USA) using primer 1055 F (GGTGGTGCATGGCCG) in order to determine the sequence of the ITS region. Since all isolates had an identical sequence of the ITS region, SSU rDNA sequence was determined from only a single one (CB) using primers 16S1, 514F (GTGCCAGCMGCCGCGG), 1385R (GATCCTAACATTGTAGC), 1055R (CGGCCATGCACCACC), 665R (ATACWCTAAGCGTCCTG), and 295R (AGTCCGACGGTAACCGC). Sequence data reported in this paper are available in GenBank under accession numbers KM095107 and KM095108.

We used R 2.12.0 (R Core Team 2010) for statistical analysis of the infection (binomial response - positive versus negative test). A series of models was created in order to shed light on the effect of individual variables. Three factors were taken into consideration: the sex of the nestling, the locality and the number of nestlings in the nest. Finally, the nested model with the effect of year was used. The data were tested for overdispersion $(<1)$ before the statistical analysis was performed. Comparisons of the models using ANOVA function followed after removal of each
Table 1. Number of nests and nestlings related to the presence of trichomonads in urban and rural areas of the Czech Republic during 2012-2013.

\begin{tabular}{lcccccccc}
\hline & \multicolumn{4}{c}{2012} & \multicolumn{4}{c}{2013} \\
\hline Locality & infected nests & infected chicks & infected nests & infected chicks \\
\hline & $\mathrm{n}$ & $\%$ & $\mathrm{n}$ & $\%$ & $\mathrm{n}$ & $\%$ & $\mathrm{n}$ & $\%$ \\
\hline Urban & 8 & 35 & 31 & 33 & 2 & 11 & 4 & 5 \\
Rural & 3 & 18 & 9 & 12 & 3 & 21 & 9 & 17 \\
\hline
\end{tabular}

Urban - Prague; rural - rural Liberec region.

term and their interactions and only the factors of which removal indicated statistically significant change $(\mathrm{P}<0.05)$ were retained in the resulting model.

\section{RESULTS}

The presence of trichomonads was tested in 168 nestlings from 23 urban nests (94 nestlings) and 17 rural nests (74 nestlings) in 2012 and in 130 nestlings from 19 urban nests (76 nestlings) and 14 rural nests (54 nestlings) in 2013. The presence of trichomonads was detected in 31 and 4 nestlings in Prague and 9 and 9 nestlings in Liberec region in 2012 and 2013, respectively (Table 1). In spite of the high percentage of parasitised birds in 2012, only a few birds with macroscopic lesions in the oral cavity were found. In contrast, all positively tested birds in 2013 showed necrotic lesions in the oral cavity. Statistical analysis revealed that triple interactions (year : sex : pull) were not significant $\left(\chi^{2}=10.232\right.$, df $\left.=6, P=0.115\right)$ and were consequently removed from following analyse. Male and female chicks were both infected without statistical significance $\left(\chi^{2}=3.203, \mathrm{df}=2, \mathrm{P}=0.201\right)$. The prevalence of infection caused by trichomonads in sparrowhawk nestlings was different between the two areas $\left(\chi^{2}=6.184\right.$, df $=2$, $\mathrm{P}=0.045)$. The number of nestlings in the nest was also found to have a highly significant result $\left(\chi^{2}=28.19, \mathrm{df}=2\right.$, $\mathrm{P}<0.001)$, i.e. it affects the prevalence of trichomonads among the sparrowhawk nestlings. The infection risk in the urban area of Prague in 2012 was higher with more nestlings in the nest. However, the infection risk declined with more nestlings on the nest in the rural area of Liberec region in 2012. The results from 2013 show similar pattern for both the urban and rural environments (Fig. 2).

Sequences of the ITS region of all nine isolates were identical and showed 98-100\% homology with sequences of Trichomonas gallinae in GenBank. Phylogenetic analysis indicated that our isolates belong to the T. gallinae genotype $\mathrm{B}$ as defined by Sansano-Maestre et al. (2009), and sequence group A as defined by Gerhold et al. (2008) (not shown). More specifically, they were identical with 15 GenBank sequences that represented 93 isolates obtained from birds of prey, songbirds, columbids and parrots in Europe, North America and Australasia (Table 2). The SSU rDNA sequence of the isolate CB was identical with the GenBank sequence HG008106 of T. gallinae obtained from various European finches (Ganas et al. 2014), confirming species identity of our isolates. 

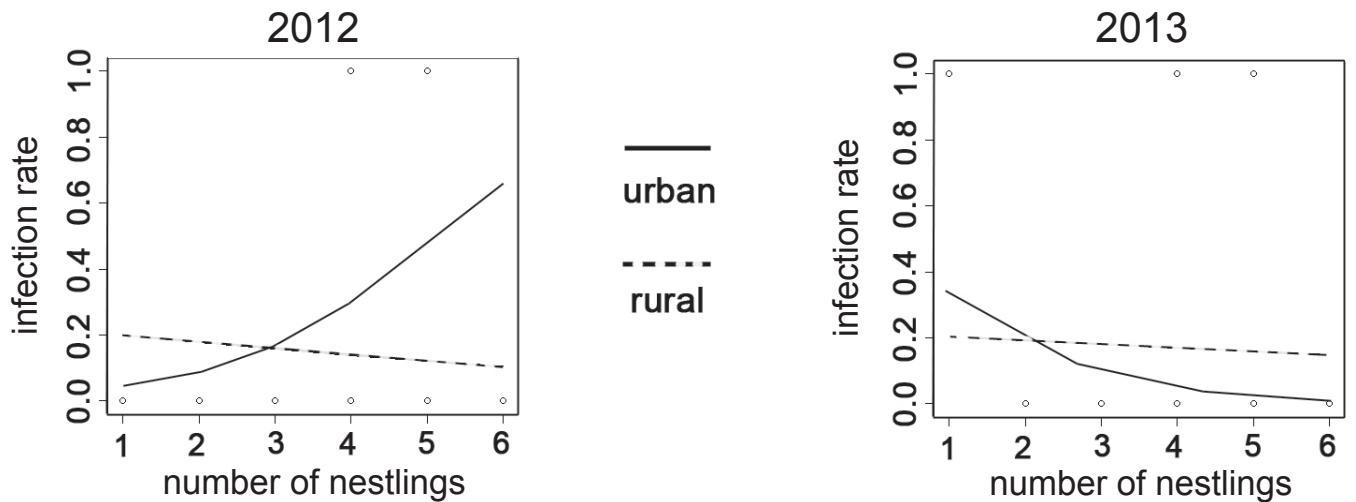

Fig. 2. Infection rate of Trichomonas gallinae (Rivolta, 1878) in Eurasian sparrowhawk, Accipiter nisus (Linnaeus), versus brood size in urban and rural areas 2012-2013.

Table 2. List of hosts infected by Trichomonas gallinae (Rivolta, 1878) with identical ITS region, their GenBank accession numbers and additional information.

\begin{tabular}{|c|c|c|c|c|}
\hline Host & GenBank sequence & Isolate(s) & Origin & Reference \\
\hline \multicolumn{5}{|l|}{ Birds of prey } \\
\hline Accipiter cooperi (Bonaparte) & EU215369 & Cooper's hawk 4 & USA & Gerhold et al. (2008) \\
\hline Accipiter nisus (Linnaeus) & KM085108 & $\mathrm{CB}(+8$ others $)$ & Czech Republic & Present study \\
\hline Aquila fasciata (Vieillot) & EU881915 & R1905 & Spain & Sansano-Maestre et al. (2009) \\
\hline Falco tinnunculus Linnaeus & EU881916 & R2015 & Spain & Sansano-Maestre et al. (2009) \\
\hline Tyto alba (Scopoli) & EU881913 & R506 & Spain & Sansano-Maestre et al. (2009) \\
\hline \multicolumn{5}{|l|}{ Songbirds } \\
\hline \multirow[t]{2}{*}{ Carduelis chloris (Linnaeus) } & HG008050 & $8800-3-\mathrm{C} 1$ (+ 60 others) & Austria & Ganas et al. (2014) \\
\hline & HG008050 & TGAL-A, TGAL-B & Slovenia & Ganas et al. (2014) \\
\hline Carpodacus mexicanus (Statius Müller) & EU290649 & n.a. & USA & not published \\
\hline Coccothraustes coccothraustes (Linnaeus) & HG008050 & 000091 & Austria & Ganas et al. (2014) \\
\hline Emberiza citrinella Linnaeus & HG008050 & $1914-2$ & Austria & Ganas et al. (2014) \\
\hline Fringilla coelebs Linnaeus & HG008050 & TGAL-SCIN & Slovenia & Ganas et al. (2014) \\
\hline Fringilla montifringilla Linnaeus & HG008050 & TGAL-PIN & Slovenia & Ganas et al. (2014) \\
\hline Haemorhous mexicanus (Statius Müller) & EU215369 & House finch 1 & USA & Gerhold et al. (2008) \\
\hline \multicolumn{5}{|l|}{ Columbids } \\
\hline 'Australasian columbid' & JQ755279 & BBK $(+4$ others $)$ & ‘Australasia' & not published \\
\hline 'Australasian columbid' & JQ755282 & CLV1 & 'Australasia' & not published \\
\hline 'Australasian columbid' & JQ755281 & BGH & 'Australasia' & not published \\
\hline 'Australasian columbid' & JQ755280 & SPT & 'Australasia' & not published \\
\hline ‘Australasian columbid' & JQ755279 & $\mathrm{BBK}$ & 'Australasia' & not published \\
\hline \multirow[t]{2}{*}{ Columba livia Gmelin } & EU215369 & Rock pigeon 8 ( +6 others $)$ & USA & Gerhold et al. (2008) \\
\hline & HG008050 & 021337 & Austria & Ganas et al. (2014) \\
\hline Columba sp. & AY349182 & G7 & n.a. & Kleina et al. (2004) \\
\hline \multirow[t]{2}{*}{ Patagioenas fasciata (Say) } & EU215369 & Band-tailed pigeon 1 & USA & Gerhold et al. (2008) \\
\hline & KC215387 & CA005882, CA015554 & USA & Girard et al. (2014) \\
\hline Streptopelia decaocto (Frivaldszky) & JX089398 & St. Kitts 21 & St. Kitts and Nevis & Ecco et al. (2012) \\
\hline Zenaida macroura (Linnaeus) & EU215369 & ATCC 30095 (+ 6 others) & USA & Gerhold et al. (2008) \\
\hline \multicolumn{5}{|l|}{ Parrots } \\
\hline Melopsittacus undulatus (Shaw) & JN007005 & Vienna $5895-\mathrm{C} 1 / 06$ & Austria & Reinmann et al. (2012) \\
\hline
\end{tabular}

n.a. - not available.

\section{DISCUSSION}

The origin of Trichomonas gallinae in sparrowhawks is unknown but feeding on infected prey such as pigeons and songbirds is considered the most likely source (Krone et al. 2005). For a better understanding of the prevalence of the disease in sparrowhawk chicks, long-term study would be necessary. Nevertheless, results show a certain similarity in the prevalence of trichomonosis in sparrowhawk chicks from the rural area. Contrary to the rural area the urban area shows a year-on-year difference. Based on the results, it is possible that the natural prevalence of trichomonosis in sparrowhawk chicks is somewhere between $5 \%$ and $15 \%$. This is similar to other accipiter hawks in rural areas such as the northern goshawk (Accipiter gentilis) (Linnaeus) (Cooper and Petty 1988) and Cooper's hawk - Accipiter cooperii (Bonaparte) (Boal et al. 1998). There was a considerably higher infection rate in sparrowhawk chicks in the urban area in 2012. Such a situation could be caused by the pandemic outbreak of trichomonosis in songbirds in the central part of the Czech Republic reported by the State 
Veterinary Administration and Czech Birdlife (Duben and Vermouzek 2012). Brood size obviously has a significant effect on the prevalence of trichomonads among the nestlings. In the event that the pandemic outbreak in the central Czech Republic had a detrimental effect on songbird populations and reduced numbers of some passerine species like in other countries (Robinson et al. 2010), sparrowhawks could respond to such changes by alteration of diet.

The urban population could transfer to feeding on columbids and thereby increase their chance of getting the infection. However, because the prevalence of trichomonosis in Prague's columbids is not known, this could be only one of many explanations. Another factor, responsible for the higher prevalence in larger broods in urban sparrowhawks, could be stress. In case of a decline in small-sized birds, due to a pandemic outbreak in the central area of the Czech Republic, larger broods of sparrowhawks could suffer from shortage of food. Subsequently, the stressed chicks would a have higher chance of developing the disease through reduced immunity. In addition, coping with other factors specific to urban environment, which affect physiological stress, can be important disease spread among nestlings (Koolhaas et al. 1999).

Little is known about the differences in diet between the urban and rural sparrowhawk populations in the Czech Republic. Although the female sparrowhawk is able to predate on fully grown woodpigeons (Newton 1986), it is doubtful that pigeons are in a sparrowhawk's diet on a regular basis. In Prague where the concentration of pigeons is high, there is a higher chance of encountering weak and diseased pigeons that could be easily predated by sparrowhawks. Prey remains of columbids were found near the urban nests by the authors during the study. Urban pigeons were found to be highly infected by trichomonosis in several cities. Borgwardt (1996) detected T. gallinae in $89.6 \%$ of free-living feral pigeons from Halle/Saale in Germany.

If the prevalence in sparrowhawk chicks in the urban area in 2013 showed a similar pattern to 2012, we could assume that the high concentration of pigeons may play a role in the incidence of trichomonosis in sparrowhawks in this urban area. Although pigeons provide a large amount of food for the brood, it is small and medium-sized birds that dominate the diet (Newton 1986, Bujoczeck and Ciach 2009). Explanation for such difference in prevalence of trichomonosis in sparrowhawk chicks in urban area in 2012 and 2013 is unfeasible due to many factors but the pandemic outbreak is the most likely the explanation.

The pathogenesis of trichomonosis in birds could be affected by several factors such as prevailing environmental conditions, physiology of the host and parasite, viability and quality of food, sibling competition and stress (Greiner and Ritchie 1994). The immunity of the individual also af-

\section{REFERENCES}

Boal C.W., Mannan R.W., Hudelson K.S. 1998: Trichomoniasis in Cooper's hawks from Arizona. J. Wild. Dis. 34: 590-593.

BorgwardT J. 1996: Untersuchungen zur Ekto- und Endoparasitenbürde bei Tauben (Columba livia forma domestica) aus dem fects the development of the infection (Samour et al. 1995). Also, the disease would mainly develop in broods raised by younger-adult birds, which might be related to lower experience, resulting in poor chick condition (Newton 1979).

The presence of $T$. gallinae in adult sparrowhawks was not investigated during this study but some adult sparrowhawks in Prague were found to show signs of trichomonosis (L. Peške, Prague, Czech Republic - unpubl. data). Adult birds are probably less susceptible to infection than nestlings (Urban and Mannan 2014). Several nestlings showed visible signs of infection during sample collection. Granulomatous caseous growths within the oral cavity in some birds were developed to a state that they obviously prevented the bird from taking food. The presence of necrotic lesions in sparrowhawk nestlings during sampling differed between years.

The actual presence of the lesions is affected by some factors; environmental conditions, time of contamination, condition of the individual (Honigberg 1979). Another factor is the presence of other infections such as Pseudomonas aeruginosa (Schroeter, 1872) (Samour 2000). Such presence of other infectious organisms was not investigated. The mortality caused by trichomonosis in sparrowhawk nestlings was not measured but could be a limiting factor for the growth of the population, as in other species (Boal et al. 1998).

Sequences of the ITS region of all our isolates were identical with of $T$. gallinae already described those in other studies. Those organisms, with identical ITS sequences, were isolated from various hosts from different continents such as America and Europe. The strain found in sparrowhawks is the same as that found in other birds such as passerines and columbiforms in Europe (Lawson et al. 2011, Ganas et al. 2014). The parasite transmission between columbids and passerine populations is probably through sharing food and water sources. The appearance of trichomonosis in sparrowhawks in the Czech Republic could be related to the spread of this disease from the UK to Fennoscandia and later to Central Europe reaching Austria and Slovenia in 2012 (Ganas et al. 2014).

The present study monitored trichomonosis in sparrowhawk chicks in a relatively small area of the Czech Republic. Further monitoring and research is needed to understand the prevalence of $T$. gallinae in prey species, especially in urban environments, the susceptibility of adult birds to trichomonosis, as well as the ecological factors and kind of prey related to the spread of the disease.

Acknowledgements. The project was funded by the Internal Grant Agency of the Faculty of Environment ČZU Prague (grant no.: 20134251 and 20124224). We thank Miroslav Šálek and anonymous referees for their comments. We are also indebted to persons who helped in the field work.

Stadtgebiet von Halle Leipzig, Vet. Med. Diss., Universität Leipzig, 92 pp.

Bujoczex M., Ciach M. 2009: Seasonal changes in the avian diet of breeding sparrowhawks Accipiter nisus: how to fulfil the offspring's food demands? Zool. Studies 48: 215-222. 
Č́epicka I., Kutišová K., Tachezy J., Kulda J., Flegr J. 2005: Cryptic species within the Tetratrichomonas gallinarum species complex revealed by molecular polymorphism. Vet. Parasitol. 128: 11-21.

Chace J.F., Walsh J.J. 2006: Urban effects on native avifauna: a review. Land. Urb. Plan. 74: 46-69.

Chi J.F., Lawson B., Durrant C., Beckmann K., John S., Alrefaei A.F., Kirkbride K., Bell D.J., Cunningham A.A., TYLER K.M. 2013: The finch epidemic strain of Trichomonas gallinae is predominant in British non-passerines. Parasitology 140: $1234-1245$.

Cooper J.E., Petty S.J. 1988: Trichomoniasis in free-living goshawks (Accipiter gentilis gentilis) from Great Britain. J. Wild. Dis. 24: $80-87$.

Cover A.J., Harmon W.M., Thomas M.W. 1994: A new method for the diagnosis of Trichomonas gallinae infection by culture. J. Wild. Dis. 30: 457-459.

DiAMOND L.S. 1957: The establishment of various trichomonads of animals and man in axenic cultures. J. Parasitol. 43: 488-490.

Duben J., VermouzeK Z. 2012: [Greenfinches die due to the protozoan's infection, humans are not in danger], http://cso.cz/index.php?ID=2333, 5/2012. (In Czech.)

Ecco R., Preis I. S., Vilela D. A., Luppi M. M., Malta M. C., Beckstead R. B., Stimmelmayer R., Gerhold R. W. 2012 Molecular confirmation of Trichomonas gallinae and other parabasalids from Brazil using the 5.8S and ITS-1 rRNA regions. Vet. Parasitol. 190: 36-42.

Fraissinet M., Fulgione D. 2008: Comparative analysis of the breeding avifauna of Italian cities. Avocetta 32: 21-30.

Fuchs R., Š́opek J., Formánek J., Exnerová A. (Eds.) 2002: [Altas of Prague Birds' Breeding Distribution.] Consult, Praha, 317 pp. (In Czech.)

Ganas P., Jaskulska B., Lawson B., Zadravec M., Hess M., BILIC I. 2014: Multi-locus sequence typing confirms the clonality of Trichomonas gallinae isolates circulating in European finches. Parasitology 141: 652-661.

Gerhold R.W., Yabsley M.J., Smith A.J., Ostergaard E., Mannan W., Cann J.D., Fischer J.R. 2008: Molecular characterization of the Trichomonas gallinae morphologic complex in the United States. J. Parasitol. 94: 1335-1341.

Girard Y.A., Rogers K.H., Gerhold R., Land K.M., LenGham S.C., Woods L.W., Haberkern N., Hopper M., Cann J.D., Johnson C.K. 2014: Trichomonas stableri n. sp., an agent of trichomonosis in Pacific Coast band-tailed pigeon (Patagioenas fasciata monilis). Int. J. Parasitol. Parasites Wildl. 3: 32-40.

Greiner E.C., Ritchie B.W. 1994: Parasites. In: B. W. Ritchie, G. J. Harrison and L. R. Harrison (Eds.), Avian Medicine: Principles and Application. Wingers Publishing, Lake Worth, Florida, pp. 1007-1029.

Honigberg B.M. 1979: Biological and physiological factors affecting pathogenicity of trichomonads. In: M. Levandowsky and S.H. Hutner (Eds.), Biochemistry and Physiology of Protozoa, Vol. 2, Academic Press, Inc. New York, pp. 409-427.

Kleina P., Bettim-Bandielli J., Bonatto S.L., Benchimol M., Bogo M.R. 2004: Molecular phylogeny of Trichomonadidae family inferred from ITS-1, 5.8S rRNA and ITS-2 sequences. Int. J. Parasitol. 34: 963-970.
Koolhass J.M., Korte S.M., Do Boer S.F:, Van Der Vegt B.J., Can Reenen C.G., Hopster H., De Jong I.C., Ruis M.A.W., BLokhuis H.J. 1999: Coping styles in animals: current status in behavior and stress-physiology. Neur. Biobehav. Rev. 23: 925-935.

Krone O., Altenkamp R., Kenntner N. 2005: Prevalence of Trichomonas gallinae in northern goshawk from Berlin Area of northeastern Germany. J. Wild. Dis. 41: 304-309.

Lawson B., Robinson R.A., Neimanis A., Handeland K., Isomursu M., Agren E.O., Hamnes I.S., Tyler K.M., Chantrey J., Hughes L.A., Pennycott T.W., Simpson V.R., John S.K., Peck K.M., Toms M.P., Bennett M., Kirkwood J.K., Cunningham A.A. 2011. Evidence of spread of the emerging infectious disease, finch trichomonosis, by migrating birds. Ecohealth 8: 143-153.

Newton I. (Ed.) 1979: Population Ecology of Raptors. T. and A.D. Poyser, Berkhamsted, $399 \mathrm{pp}$.

Newton I. (Ed.) 1986: The sparrowhawk. T and A.D. Poyser, Calton, $396 \mathrm{pp}$.

Phan T.G., Vo N.P., Boros A., Pankovics P., Reuter G., Li O.T.W., Wang C.L., Deng X.T., Poon L.L.M., Delwart E. 2013: The viruses of wild pigeon droppings. PLoS ONE 8: e72787.

R Core Team 2015: R: A Language and Environment for Statistical Computing. R Foundation for Statistical Computing, Vienna, Austria.

Reinmann K., Müller N., Kuhnert P., Campero C.M., Leitsch D., Hess M., Henning K., Fort M., Müller J., Gottstein B., Frey C. F. 2012: Tritrichomonas foetus isolates from cats and cattle show minor genetic differences in unrelated loci ITS-2 and EF-1 $\alpha$. Vet. Parasitol. 185: 138-144.

Robinson R.A., Lawson B., Toms M.P., Peck K.M., Kirkwood J.K., Chantrey J., Clatworthy I.R., Evans A.D., Hughes L.A., Hutchinson O.C., John S.K., Pennycott T.W., PerKins M.W., Rowley P.S., Simpson V.R., Tyler K.M., CunNINGHAM A.A. 2010: Emerging infectious disease leads to rapid population declines of common British birds. PLoS ONE 5: e12215.

Samour J.H. 2000: Pseudomonas aeruginosa stomatitis as a sequel to trichomoniasis in captive saker falcons (Falco cherrug). J. Avian Med. Surgery 14: 113-117.

Samour J.H., Bailey T.A., Cooper J.E. 1995: Trichomoniasis in birds of prey (order Falconiformes) in Bahrain. Vet. Rec. 136: $358-362$.

Sansano-Maestre J., Garijo-Toledo M.M., Gómez-Muñoz M.T. 2009: Prevalence and genotyping of Trichomonas gallinae in pigeons and birds of prey. Avian Pathol. 38: 201-207.

Selas V., Rafoss T. 1999: Ranging behaviour and foraging habitats of breeding sparrowhawks Accipiter nisus in continuous forested area in Norway. Ibis 141: 269-276.

TaChezy J., Tachezy R., Hampl V., Šedinová M., Vañáčová Š., Vrlik M., Van Ranst M., Flegr J., Kulda J. 2002: Cattle pathogen Tritrichomonas foetus (Riedmüller, 1928) and pig commensal Tritrichomonas suis (Gruby \& Delafond, 1843) belong to the same species. J. Eukar. Microbiol. 49: 154-163.

Urban E.H., Mannan R.W. 2014: The potential role of oral pH in the persistence of Trichomonas gallinae in Cooper's hawks (Accipiter cooperii). J. Wild. Dis. 50: 50-55. 